\title{
Diacylglycerol kinase a inactivation is an integral component of the costimulatory pathway that amplifies TCR signals
}

\author{
Javier Arranz-Nicolás ${ }^{1}$. Jesús Ogando ${ }^{1}$. Denise Soutar ${ }^{1} \cdot$ Raquel Arcos-Pérez $^{1}$ - Daniel Meraviglia-Crivelli ${ }^{1}$. \\ Santos Mañes ${ }^{1} \cdot$ Isabel Mérida ${ }^{1}$ (1) . Antonia Ávila-Flores ${ }^{1}[0$
}

Received: 16 August 2017 / Accepted: 19 March 2018 / Published online: 23 March 2018

๑) Springer-Verlag GmbH Germany, part of Springer Nature 2018

\begin{abstract}
The arsenal of cancer therapies has evolved to target $\mathrm{T}$ lymphocytes and restore their capacity to destroy tumor cells. $\mathrm{T}$ cells rely on diacylglycerol (DAG) to carry out their functions. DAG availability and signaling are regulated by the enzymes diacylglycerol kinase (DGK) $\alpha$ and $\zeta$, whose excess function drives T cells into hyporesponsive states. Targeting DGK $\alpha$ is a promising strategy for coping with cancer; its blockade could reinstate T-cell attack on tumors while limiting tumor growth, due to positive DGK $\alpha$ functions in several oncogenic pathways. Here, we made a side-by-side comparison of the effects of commercial pharmacological DGK inhibitors on T-cell responses with those promoted by DGK $\alpha$ and DGK $\zeta$ genetic deletion or silencing. We show the specificity for DGK $\alpha$ of DGK inhibitors I and II and the structurally similar compound ritanserin. Inhibitor treatment promoted Ras/ERK (extracellular signal-regulated kinase) signaling and AP-1 (Activator protein-1) transcription, facilitated DGK $\alpha$ membrane localization, reduced the requirement for costimulation, and cooperated with enhanced activation following DGK $\zeta$ silencing/deletion. DGKiII and ritanserin had similar effects on TCR proximal signaling, but ritanserin counteracted long-term T-cell activation, an effect that was potentiated in DGK $\alpha^{-/}$cells. In contrast with enhanced activation triggered by pharmacological inhibition, DGK $\alpha$ silencing/genetic deletion led to impaired Lck (lymphocyte-specific protein tyrosine kinase) activation and limited costimulation responses. Our results demonstrate that pharmacological inhibition of DGK $\alpha$ downstream of the TCR provides a gain-of-function effect that amplifies the DAGdependent signaling cascade, an ability that could be exploited therapeutically to reinvigorate $\mathrm{T}$ cells to attack tumors.
\end{abstract}

Keywords Diacylglycerol kinase $\cdot$ Cancer immunotherapy $\cdot$ Lck $\cdot$ T-cell activation $\cdot$ R59949 $\cdot$ Serotonin receptors

$\begin{array}{ll}\text { Abbreviations } \\ \text { 5-HT } & \text { Serotonin } \\ \text { 5-HTR } & \text { Serotonin receptor } \\ \text { AP-1 } & \text { Activator protein-1 } \\ \text { CNB } & \text { Centro Nacional de Biotecnología } \\ \text { CSIC } & \text { Consejo Superior de Investigaciones Científicas } \\ \text { DAG } & \text { Diacylglycerol } \\ \text { DGK } & \text { Diacylglycerol kinase }\end{array}$

Electronic supplementary material The online version of this article (https://doi.org/10.1007/s00262-018-2154-8) contains supplementary material, which is available to authorized users.

Isabel Mérida

imerida@cnb.csic.es

$\triangle$ Antonia Ávila-Flores jaavila@cnb.csic.es

1 Department of Immunology and Oncology, Centro Nacional de Biotecnología (CNB-CSIC), Darwin 3, UAM Campus de Cantoblanco, 28049 Madrid, Spain

$\begin{array}{ll}\text { DGKi } & \text { DGK inhibitor } \\ \text { ERK } & \text { Extracellular signal-regulated kinase } \\ \text { HM-1 } & \text { Human muscarinic receptor-1 } \\ \text { Lck } & \text { Lymphocyte-specific protein tyrosine kinase } \\ \text { NFAT } & \text { Nuclear factor of activated T cells } \\ \text { PLC } & \text { Phospholipase C-gamma } \\ \text { WT } & \text { Wild type }\end{array}$

\section{Introduction}

Harnessing productive T-cell responses to tumors is an effective strategy in the fight against cancer. Engineering $\mathrm{CD} 8^{+}$ $\mathrm{T}$ cells to express CAR shows excellent results for treatment of hematological malignancies [1]. The success of this strategy for solid tumor therapy has nonetheless proven limited, which suggests that even artificial strong TCR signals do not impede intrinsic tumor-triggered inhibitory programs in TIL [2]. Antibodies that block receptors with negative 
regulatory functions in TIL (immune checkpoint-blocking $\mathrm{Ab}$ ) have yielded excellent results in treatment of melanoma and other solid tumors $[3,4]$. The inhibition of cytosolic regulators that limit TCR signal strength represents another means to overcome tumor-induced immunosuppression [5].

Diacylglycerol kinases (DGK) transform diacylglycerol (DAG) into phosphatidic acid (PA), thus limiting DAG-regulated functions [6]. T lymphocytes express two isoforms, DGK $\alpha$ and $\zeta$, which operate downstream of the TCR [7]. Excessive DGK $\alpha / \zeta$ function attenuates DAG-dependent Ras/ ERK (extracellular signal-regulated kinase)/AP-1 (activator protein-1) and $\mathrm{PKC} \theta / \mathrm{NF \kappa B}$ transcription, which produces an imbalance of these pathways relative to $\mathrm{Ca}^{2+}$-mediated NFAT (nuclear factor of activated T cells) activation. Negative regulators of TCR signals, including immune checkpoints, ubiquitin ligases, and/or phosphatases, have NFATresponsive regulatory elements in their promoters [8]; as a result, excessive DGK-dependent DAG consumption drives $\mathrm{T}$ cells into hyporesponsive, anergic states. The anergyresistant phenotype of DGK $\alpha / \zeta$-deficient mice confirms their contribution as intrinsic inhibitors of T-cell responses [9].

Experimental evidence suggests that enhanced DGK function/expression in TIL limits tumor destruction. When injected into nude mice bearing engrafted mesothelioma tumors, tumor-infiltrating human CAR T cells show higher DGK $\alpha / \zeta$ expression than spleen-isolated cells [5]. DGK $\alpha$ expression is also enhanced in TIL isolated from human renal tumors [10]. These studies support a rationale for targeting DGK $\alpha / \zeta$ in the development of anticancer therapies. Indeed, the impaired cytotoxic activity of renal TIL and mesothelioma-infiltrated CAR T cells can be recovered in vitro after treatment with commercial DGK inhibitors (DGKi) [5, 10]. These drugs are stronger inhibitors of DGK $\alpha$ than of DGK $\zeta[11]$. The reversal of hypofunctional TIL phenotypes by DGKi contrasts with the observation that $\mathrm{DGK} \alpha^{-1-} \mathrm{CTL}$ does not show enhanced cytotoxicity [12]. The design of effective therapies to limit DGK activation demands a better understanding of isoform-specific functions, as well as of the mechanisms triggered by DGK inhibition.

We undertook a detailed study of the results of pharmacological blockade of DGK $\alpha$ activity compared to those fostered by its genetic deletion/silencing. We compared the effects of DGKiI/II with those of ritanserin, a structurally similar compound originally conceived to treat mental disorders [13, 14]. Initially characterized as a serotonin (5-HT) type 2 receptor $\left(5-\mathrm{HTR}_{2}\right)$ antagonist $[13,14]$, ritanserin was recently shown to inhibit DGK $\alpha$ in vitro [15]. DGKiI (R59022) and II (R59949) have restricted benefit in vivo, since they are effective in the micromolar range and have limited solubility $[11,16]$. Ritanserin has superior pharmacokinetic properties and is considered safe for human use [17], suggesting its potential use for DGK $\alpha$ inhibition. Our experiments confirmed DGKi and ritanserin as DGK $\alpha$ inhibitors, as their effects were lost after DGK $\alpha$ silencing or genetic deletion, but were maintained in DGK $\zeta$-silenced/ deleted cells. DGKi and ritanserin enhanced early T-cell signaling, but ritanserin antagonism of specific 5-HTR reduced expression of activation markers, which limited its effectiveness as a DGK $\alpha$ inhibitor. DGK $\alpha$ silencing or genetic deletion correlated with impaired Lck (lymphocyte-specific protein tyrosine kinase) activation and limited costimulation responses. In contrast, pharmacological DGK $\alpha$ targeting provides a gain-of-function effect that amplifies T-cell responses, and must be considered in the search for and design of DGK-based therapeutic strategies.

\section{Materials and methods}

\section{Mice}

C57BL/6J-DGK $\alpha^{-/-}$and the OT-I DGK $\alpha^{-1-}$ and OT-I DGK $\zeta^{-/-}$mice have been described $[9,18,19]$.

\section{Reagents}

Carbachol, R59949, R59022, ritanserin, and ketanserin were from Sigma-Aldrich. OVA peptides were from AnaSpec.

\section{Isolation, culture, and stimulation of murine and human $T$ cells}

Thymus, spleen, or LN was purified from 6- to 12-weekold mice. Cells were cultured in complete RPMI medium (cRPMI), consisting of RPMI (Invitrogen) with 10\% heatinactivated FBS (Invitrogen), $2 \mathrm{mM} \mathrm{L}$-glutamine, $1 \%$ HEPES (Sigma). cRPMI was supplemented with penicillin and streptomycin $(100 \mathrm{U} / \mathrm{ml})$, and $50 \mu \mathrm{M} 2-\mathrm{ME}\left(37^{\circ} \mathrm{C}, 5 \%\right.$ $\mathrm{CO}_{2}$ ). TCR crosslinking of thymocytes and long-term $\mathrm{LN}$ stimulation for activation marker expression analysis were as described [19].

Splenocytes from OT-I transgenic mice were stimulated with OVA $257-264$ (SIINFEKL), Q4 (SIIQFEKL), and Q4H7 (SIIQFEHL) peptides [19].

For CTL differentiation, LN cells from OT-I mice were activated with $10 \mathrm{nM} \mathrm{OVA}_{257-264}(48 \mathrm{~h})$, and then diluted $\left(10^{5}\right.$ cells $\left./ \mathrm{ml}\right)$ and cultured with $100 \mathrm{U} / \mathrm{ml} \mathrm{IL}-2$ (4 days).

Human leukemic Jurkat T cells (ATCC) were cultured in cRPMI and stimulated with anti-CD3 alone or with antiCD28 $\left(10^{7}\right.$ cells $/ \mathrm{ml}, 1 \mu \mathrm{g} / \mathrm{ml}$ of each $\left.\mathrm{mAb}\right)$ for indicated times [19]. The J-HM1-2.2 cell line was generated by stable transfection of the human muscarinic receptor-1 (HM-1) in Jurkat cells [20] and stimulated with $50 \mu \mathrm{M}$ carbachol for indicated times.

PBMC were obtained from healthy donors, prepared from buffy coats in a Ficoll density gradient, and $\mathrm{CD} 8^{+} \mathrm{T}$ cells 
purified using an enrichment kit (Stem Cell Technologies). Cells were cultured in cRPMI at a 1:3.5 ratio with tosylactivated magnetic beads (Dynabeads M-450; Thermo Scientific) coated according to manufacturer's protocols with $100 \%$ control IgG1 (R\&D Systems), or with $8 \%$ anti-CD3 (HIT3a, BD Biosciences), 10\% anti-CD28 (CD28.2, BioLegend), and $82 \%$ control IgG1 or $82 \%$ PD-L1-Fc chimera protein (R\&D Systems).

After stimulation, cells were collected and incubated with indicated $\mathrm{Ab}$ and analyzed by flow cytometry, or were lysed and analyzed by western blot according to standard protocols [19]. Unless otherwise indicated in the figure, R59949, $\mathrm{R} 59022$, ritanserin, or ketanserin was added to a $15 \mu \mathrm{M}$ concentration.

\section{Plasmids and transfection}

Silencing experiments and cell transfection by electroporation were as reported using Gene Pulser II (BioRad) [19]. The GFP-fused DGK $\alpha$ constructs have been described [21]. Reporter plasmids for AP-1 and NFkB were constructed in the pGL3 basic vector (Promega) using a tandem of four AP-1 canonic binding sites and the NFKB-containing region of the human CD69 promoter, respectively. The IL-2 promoter was from Addgene.

\section{Flow cytometry analysis}

Mouse T cells were stained with anti-CD8-APC eFluor 780 (BD Biosciences), -CD69-PE and CD25-PE/Cy7 (BD Pharmingen). Cell viability was assessed by Live/Dead Fixable Violet Cell Stain (Thermo Fisher).

For pERK analysis of OT-I transgenic cells, total splenocytes $\left(10^{6}\right)$ were cultured in peptide-containing medium (40 min), fixed in $1 \%$ paraformaldehyde (10 min, RT), and permeabilized using Phosflow Perm Buffer III (BD Biosciences; $30 \mathrm{~min}, 4{ }^{\circ} \mathrm{C}$ ). Cells were stained for surface markers (anti-mouse CD8 Pacific Blue and -CD44 PECy5; 15 min, RT), washed, incubated with anti-pERK (ERK1 + ERK2; D13.14.4 XP, Cell Signaling; 1 h, RT), washed and stained with secondary goat $\mathrm{F}\left(\mathrm{ab}^{\prime}\right) 2$ anti-rabbit IgG $(\mathrm{H}+\mathrm{L})$-PE Ab (Beckman Coulter; 15 min, RT).

Jurkat cells were stained with anti-human CD69-PC5 and CD25-PE (Beckman Coulter). For pERK analysis in Jurkat cells, $2 \times 10^{6}$ cells were stimulated $(15 \mathrm{~min}$ ), fixed (10 min, RT; $2 \%$ formaldehyde), permeabilized (ice-cold $90 \%$ methanol; $30 \mathrm{~min}, 4{ }^{\circ} \mathrm{C}$ ), washed, and suspended in staining medium (PBS, $1 \%$ BSA, $0.1 \% \mathrm{NaN}_{3}$ ). Following anti-pERK incubation $\left(30 \mathrm{~min}, 4{ }^{\circ} \mathrm{C}\right.$ ), cells were washed, stained with secondary $\mathrm{Ab}\left(30 \mathrm{~min}, 4^{\circ} \mathrm{C}\right)$ and analyzed.

Human $\mathrm{CD}^{+} \mathrm{T}$ cells were stained with anti-human CD8FITC, -CD69-PC5, and -CD25-PE.
Cells were analyzed in a Gallios flow cytometer (Beckman Coulter). Data were analyzed with FlowJo software (FlowJo LLC, Ashland, OR). In all cases, MFI refers to the positive population for each marker.

\section{Dual luciferase reporter assays}

Experiments were performed as described [19]. Cells were stimulated with anti-CD3 or $-\mathrm{CD} 3 / \mathrm{CD} 28$ or carbachol $(20 \mathrm{~h})$. Where indicated, DGKi was included in the stimulation. Cells were harvested and assayed for luciferase activity using the Dual Luciferase Reporter Assay (Promega). Luciferase activity was reported relative to renilla luciferase activity (RLU).

\section{Immunofluorescence microscopy and western blot}

J-HM1-2.2 cells were transfected with the porcine GFPDGK $\alpha$ wild type (wt) construct and analyzed [21]. Antibodies used for western blot were anti-pERK, -pSrc family kinases Tyr394, -pLck Tyr505, -pPLC $\gamma$, and -pZap70 Tyr319 (Cell Signaling), -p59Lck (Pharmingen), -Zap70 (BD Transduction Laboratories), -GAPDH (Santa Cruz), -GFP (Invitrogen), -PLC $\gamma$ (Millipore), -phospho-tyrosine (clone 4G10; Millipore), -pNFkB Ser311, -DGK (Abcam), and $-\alpha$-tubulin mAb (Sigma). Anti-hDGK $\alpha$ was a gift of Dr. W. van Blitterswijk (NCI, Amsterdam, The Netherlands) [22]. Mouse DGK $\alpha$ was detected using an in-house rabbit antibody [23]. HRP-coupled polyclonal goat anti-mouse/ anti-rabbit Ig was from DakoCytomation.

\section{Statistical analysis}

Flow cytometry and luciferase data were analyzed with GraphPad Prism 5 software. Data are shown as mean \pm SEM. Samples were assumed to fit normality. When more than two conditions were analyzed, we applied ANOVA and Bonferroni post-test analyses. In all cases, differences were considered statistically non-significant (ns) for $p$ values $>0.05$, and significant for $* p<0.05 ; * * p<0.01$ and ${ }^{* * *} p<0.001$.

\section{Results}

\section{DGKa pharmacological blockade, but not silencing, yields gain-of-function effects on ERK/AP-1 activation}

Jurkat $\mathrm{T}$ cells bind 5-HT, although ritanserin, which preferentially blocks the 5-HTR 2 , has no 5-HT antagonistic effects in these cells [24]. This suggests that Jurkat 5-HTR are ritanserin-insensitive. We used this cell line to compare the effect of R59949 and ritanserin on ERK phosphorylation 
968

Cancer Immunology, Immunotherapy (2018) 67:965-980

a

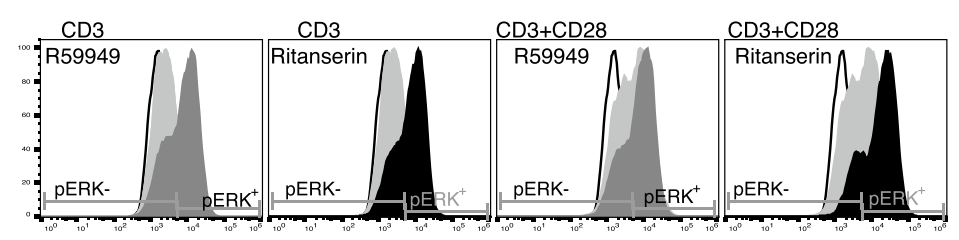

b
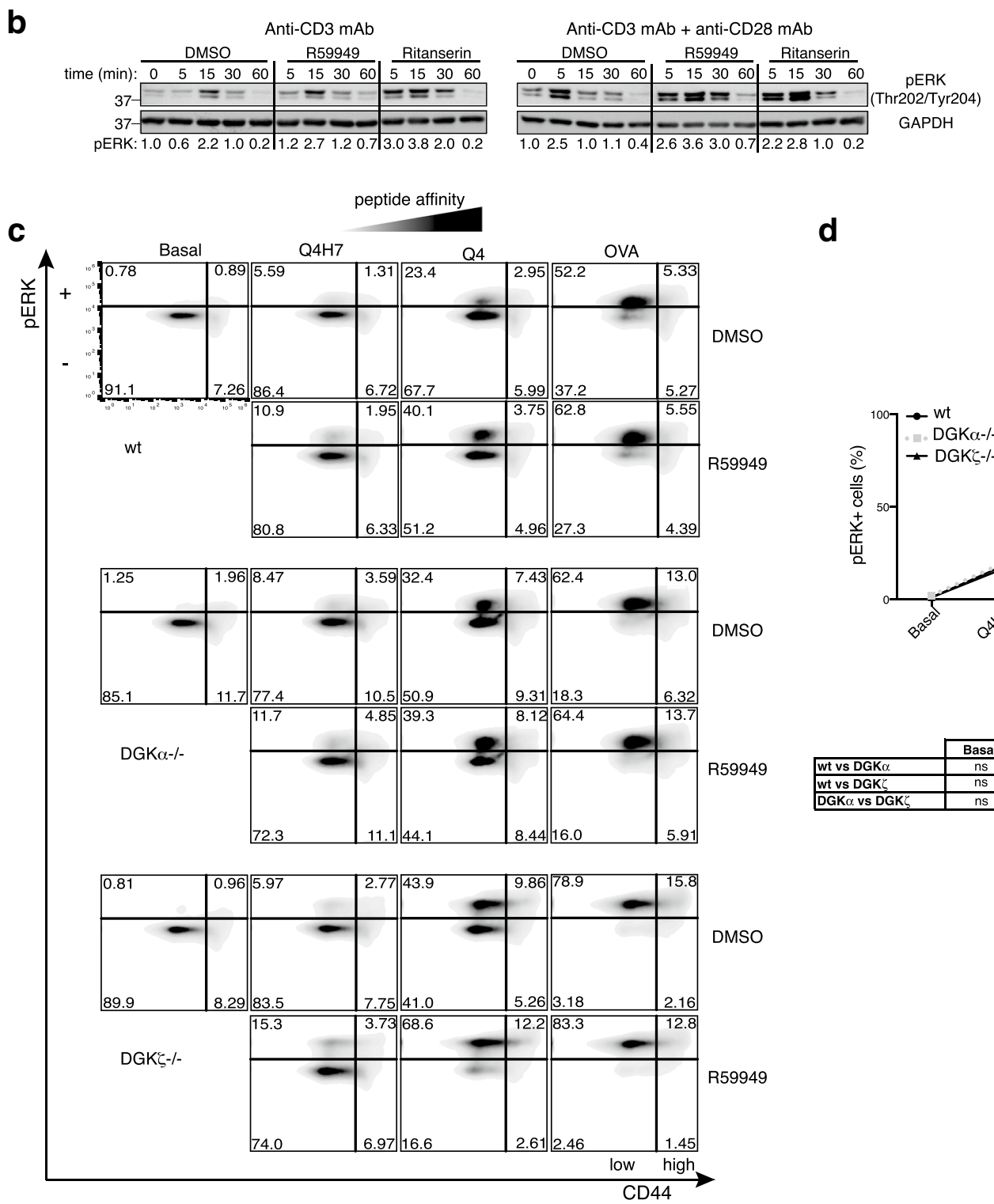

d

$$
\begin{aligned}
& \text { Basal } \\
& \text { CD3 +/- CD28 } \\
& \text { CD3 +/- CD28 + R59949 } \\
& \text { CD3 +/- CD28 + ritanserin }
\end{aligned}
$$

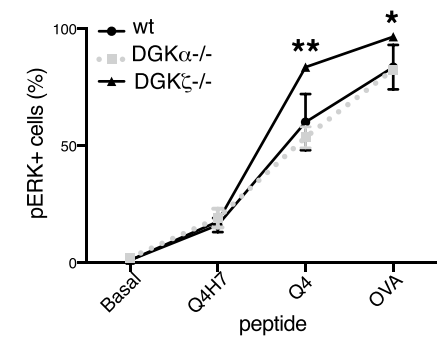

\begin{tabular}{|l|c|c|c|c|}
\cline { 2 - 5 } \multicolumn{1}{c|}{} & Basal & Q4H7 & Q4 & OVA \\
\hline wt vs DGK $\alpha$ & $\mathrm{ns}$ & $\mathrm{ns}$ & $\mathrm{ns}$ & $\mathrm{ns}$ \\
\hline wt vs DGK $\zeta$ & $\mathrm{ns}$ & $\mathrm{ns}$ & $\star \star$ & $\star$ \\
\hline DGK $\alpha$ vs DGK $\zeta$ & $\mathrm{ns}$ & $\mathrm{ns}$ & $\mathrm{ns}$ & $\mathrm{ns}$ \\
\hline
\end{tabular}

e

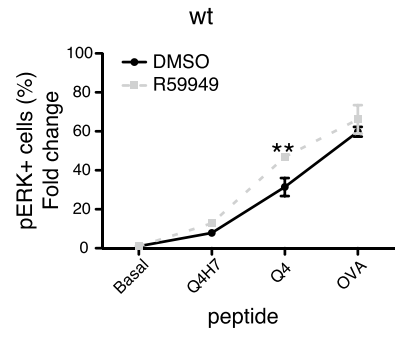

DGK $\alpha-/-$

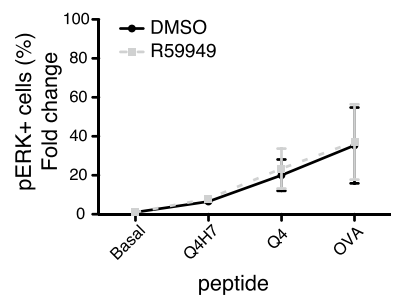

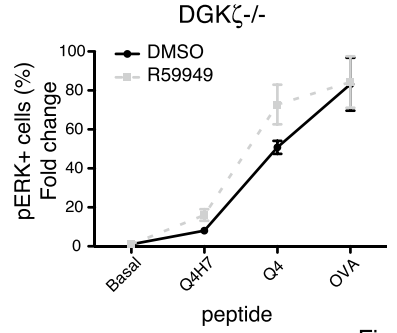

Figure 1

Springer 
४Fig. 1 DGK control of the ERK axis. a Phosphoflow analysis of ERK phosphorylation in Jurkat $\mathrm{T}$ cells stimulated with anti-CD3 or -CD3/ CD28 mAb, alone or with the DGKi. The percentage of $\mathrm{pERK}^{+}$cells is shown. b Cells were stimulated as in a and pERK evaluated by western blot. Normalized values for pERK/GAPDH ratios are indicated beneath the blots. Values were normalized to the unstimulated time point $=1.0$. c-e Splenocytes from wt or DGK ${ }^{-/-}$OT-I transgenic mice were stimulated with the indicated peptides, with DMSO or R59949. ERK1/2 phosphorylation and CD44 expression were determined by flow cytometry. c Representative biparametric analysis of $\mathrm{CD}_{4} 4^{+}$and $\mathrm{pERK}^{+}$in $\mathrm{CD}^{+}$cells of each genotype. d Percentage of $\mathrm{pERK}^{+}$cells in the $\mathrm{CD} 44^{\text {low }}$ population for the three genotypes. $\mathrm{e}$ Effect of R59949 on the percentage of pERK ${ }^{+}$cells in each genotype was determined after normalization to basal conditions. Results summarize two experiments $(n=3 /$ genotype). c-e Data were analyzed using two-way ANOVA and Bonferroni post-test. Significant differences are indicated

downstream of TCR and TCR/CD28 stimulation. Flow cytometry and western blot analyses showed that both drugs enhanced ERK phosphorylation (Fig. 1a, b; Supplementary Fig. 1a). The structurally related molecule R59022 also enhanced ERK activation, but the structurally distinct 5 -HTR 2 antagonist ketanserin did not (Supplementary Fig. 1b). This finding indicated that the effects of ritanserin and related compounds on ERK were mediated through DGK inhibition rather than by $5-\mathrm{HTR}_{2}$ antagonism.

Tumor cells can become refractory to T-cell killing by losing highly immunogenic $\mathrm{Ag}$; remaining tumor $\mathrm{Ag}$ could have low affinity for their cognate TCR [25]. DGK inhibition or elimination could potentially increase the T-cell response to low affinity $\mathrm{Ag}$, but could also render $\mathrm{T}$ cells hyper-responsive, leading to autoimmunity. We analyzed the effect of pharmacological DGK inhibition and deletion on different degrees of antigenic stimulation, using the OT-I mouse model, in which $\mathrm{CD} 8^{+} \mathrm{T}$ cells can be stimulated with the cognate peptide (OVA) or with the Q4 and Q4H7 variants, which have intermediate and low affinity for the TCR, respectively [26].

Flow cytometry analysis of the stimulated splenocytes confirmed that the number of pERK-positive cells increased with peptide affinity, mainly in the CD $44^{\text {low }}$ subset. DGK deficiency increased the percentage of OT-I $p E R K^{+}$cells and the intensity of ERK phosphorylation per cell (Fig. 1c). These increases were significant in DGK $\zeta^{-1-}$ cells, as in a previous report [27], but not for DGK $\alpha^{-1-}$ cells (Fig. 1d; Supplementary Fig. 2a). R59949 increased the number of pERK $^{+}$cells in the CD44 ${ }^{\text {low }}$ population across the affinity range (Fig. 1c). After normalization to basal conditions, we observed that in wt cells, R59949 significantly increased the percentage of $\mathrm{pERK}^{+}$cells and MFI at intermediate affinity. The inhibitor had a similar effect in DGK $\zeta^{-/-}$cells, whereas the DGK $\alpha^{-1-}$ cells showed no increase after R59949 treatment (Fig. 1e; Supplementary Fig. 2b). These data suggest that R59949-mediated DGK $\alpha$ inhibition reduced the TCR threshold for intermediate-affinity Ag.
Treatment of differentiated CTL with ritanserin or R59949 also enhanced ERK phosphorylation when cells were challenged with OVA-loaded APC. CTL from DGK $\alpha^{-/-}$mice showed enhanced ERK phosphorylation that was not increased by R59949 treatment, further confirming loss of DGKi effect in DGK $\alpha^{-/-}$cells (Supplementary Fig. 2c).

DAG-mediated regulation of the Ras/ERK pathway in response to TCR activation activates AP-1-mediated transcription. We evaluated ritanserin and R59949 effects on AP-1 transcription using parental and Jurkat $\mathrm{T}$ cells silenced for each DGK isoform (Fig. 2a). Both inhibitors enhanced TCR-dependent AP-1 transcription in parental cells (Fig. 2b). DGK $\alpha$ silencing had no effect, whereas DGK $\zeta$ silencing enhanced transcription to nearly the same extent as pharmacological blockade in controls (Fig. 2b). Inhibitor treatment further enhanced AP-1 transcription after DGK $\zeta$ silencing, with a partial effect after DGK $\alpha$ silencing, probably due to residual DGK $\alpha$ expression (Fig. 2a).

We evaluated the effect of the two inhibitors in Jurkat $T$ cells expressing a constitutive active DGK $\alpha$ mutant. Deletion of the two N-terminal EF-hand domains in DGK $\alpha$ (DGK $\alpha \Delta \mathrm{EF}$ ) triggers an open conformation with enhanced enzyme activity and constitutive plasma membrane localization [21]. Cells that transiently express DGK $\alpha \Delta \mathrm{EF}$ showed reduced AP-1 activity after TCR stimulation (Fig. 2c, left, center). R59949 or ritanserin treatment promoted TCRinduced luciferase activity in control and DGK $\alpha \Delta \mathrm{EF}-$ expressing cells, with higher fold induction in cells that overexpressed the DGK $\alpha$ mutant (Fig. 2c, right).

\section{Pharmacological DGKa inhibition sustains membrane localization}

The previous experiments strongly supported ritanserin and R59949 specificity for DGK $\alpha$, and suggested a gain-offunction effect not mimicked by DGK $\alpha$ depletion. DGK $\alpha$ localization to the plasma membrane is limited by its own activity, as shown by sustained localization in response to receptor stimulation of a kinase-defective DGK $\alpha$ mutant and/or to R59949 treatment [21]. We tested whether ritanserin-mediated DGK $\alpha$ inhibition correlated with prolonged DGK $\alpha$ localization at the cell membrane. For translocation experiments, we used J-HM1-2.2 Jurkat cells, a variant that constitutively expresses the carbachol receptor; this allows analysis of rapid DGK $\alpha$ translocation kinetics using a GFPDGK $\alpha$-expressing plasmid [21]. Carbachol addition to GFPDGK $\alpha$-expressing J-HM1-2.2 cells induced rapid, transient translocation of the recombinant protein to the membrane (Fig. 2d, top). Ritanserin addition mimicked the effect of both inhibitors, promoting sustained GFP-DGK $\alpha$ membrane localization (Fig. 2d, bottom) and enhanced AP-1 transcription (Fig. 2e). 
a

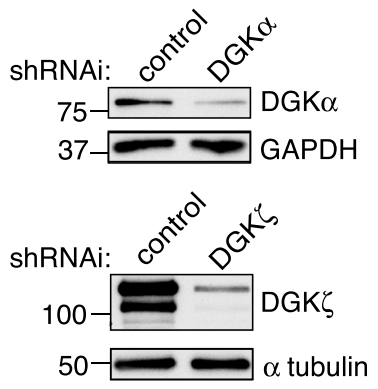

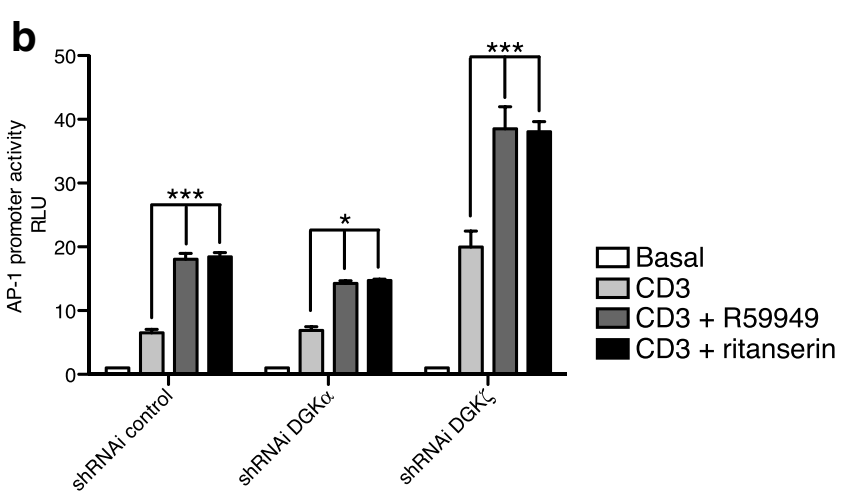

\begin{tabular}{|l|c|c|c|c|}
\cline { 2 - 5 } \multicolumn{1}{c|}{} & Basal & CD3 & CD3 + R59 & CD $3+$ rit \\
\hline control vs DGK $\alpha$ & $\mathrm{ns}$ & $\mathrm{ns}$ & $\star$ & $\star \star$ \\
\hline control vs DGK $\zeta$ & $\mathrm{ns}$ & $\star \star \star$ & $\star \star \star$ & $\star \star \star$ \\
\hline DGK $\alpha$ vs DGK $\zeta$ & $\mathrm{ns}$ & $\star \star \star$ & $\star \star \star$ & $\star \star \star$ \\
\hline
\end{tabular}

C

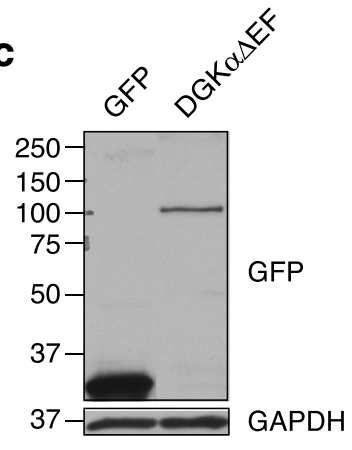

d

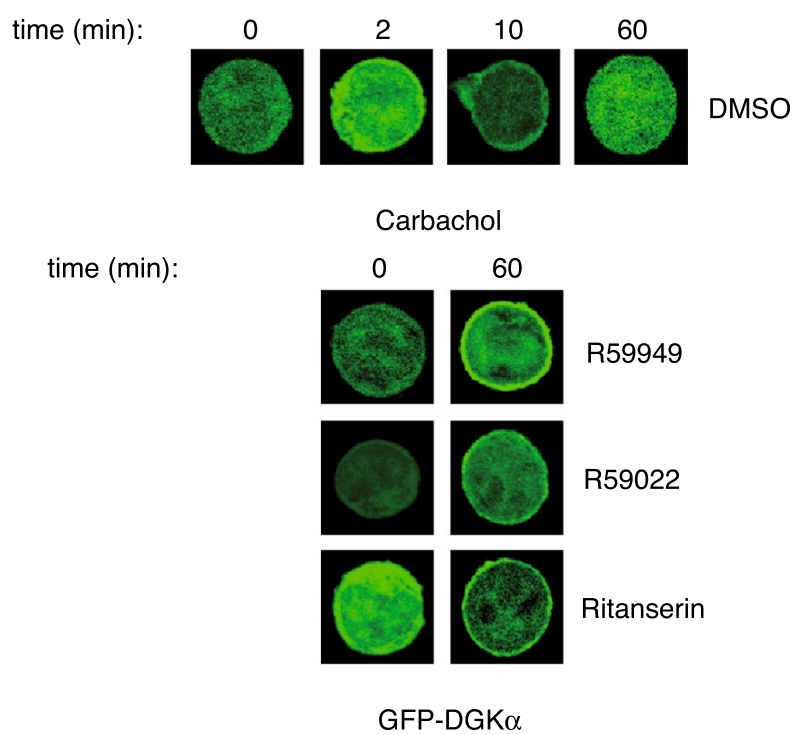

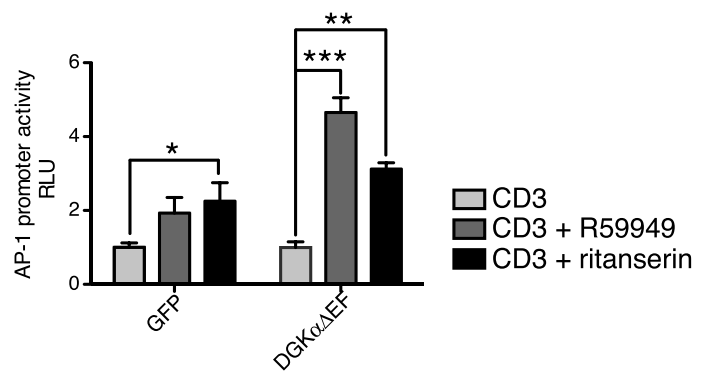

e

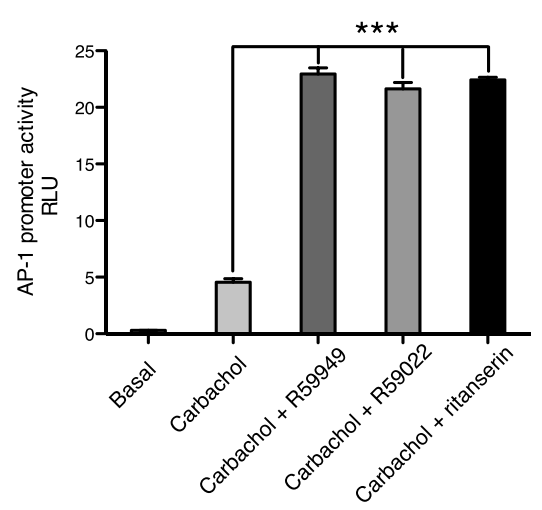


४Fig. 2 Inhibitor specificity for DGK $\alpha$. a DGK $\alpha$ or DGK $\zeta$ were silenced in Jurkat $\mathrm{T}$ cells. Silencing was confirmed by western blot using $\mathrm{Ab}$ specific for each isoform. b Luciferase activity of an AP-1 reporter construct was determined after stimulation with anti-CD3 $\mathrm{mAb}$, alone or with the indicated DGKi. c Expression of a constitutively active version of $\mathrm{DGK} \alpha(\mathrm{DGK} \alpha \Delta \mathrm{EF})$ in Jurkat $\mathrm{T}$ cells was confirmed by western blot with anti-GFP mAb (left). Luciferase activity of the AP-1 reporter was evaluated in parental and DGK $\alpha \Delta$ EF-expressing Jurkat $T$ cells, unstimulated or stimulated with CD3 (center). Values were normalized to the basal GFP condition. Effect of DGKi on luciferase activity of stimulated parental and transfected cells (right). Values were normalized to the anti-CD3 condition of each cell type. d J-HM1-2.2 T cells were transfected with a plasmid encoding GFP-DGK $\alpha$; after $24 \mathrm{~h}$, cells were carbacholstimulated for indicated times with DMSO or the indicated DGKi, and GFP localization was detected by confocal microscopy. e Effect of DGKi on luciferase activity of an AP-1 reporter construct in J-HM1-2.2 T cells stimulated with carbachol. Data shown as mean \pm SEM; $n=3$ independent transfections per shRNAi/overexpressed construct. Results are representative of at least three independent series of experiments with similar results. In $\mathbf{b}$, $\mathbf{c}$ data were analyzed using two-way ANOVA and Bonferroni post-test; in $\mathbf{b}$, results of comparisons are summarized in the table. In $\mathbf{e}$, data were analyzed with oneway ANOVA and Bonferroni post-test

\section{DGKa inhibition amplifies TCR signals}

The effect of the inhibitors on DGK $\alpha$ subcellular localization and on activation of the ERK/AP-1 axis suggests that membrane targeting of the inactive enzyme has positive functions that cannot be reproduced by enzyme silencing. Membrane localization of DGK $\alpha$ in response to TCR triggering requires of Lck (Lymphocyte-specific protein tyrosine kinase) phosphorylation [28]. In metastatic tumor cell lines, DGK $\alpha$ association with Src is necessary to sustain Src phosphorylation and Src-dependent functions [29]. We analyzed the effect of DGK $\alpha$ genetic deletion/silencing on TCR-triggered Lck activation.

$\mathrm{CD} 3 / \mathrm{CD} 28$ crosslinking of DGK $\alpha^{-/-}$thymocytes did not induce Lck activation as defined by its autophosphorylation at tyrosine 394 (pTyr394), whereas cells from wt mice showed strong phosphorylation (Fig. 3a). Lck autophosphorylation in Tyr394 was also markedly reduced in DGK $\alpha$ silenced cells, and total phospho-tyrosine profiles showed subtle decreases (Fig. 3b; Supplementary Fig. 3b). Following DGK $\alpha$ silencing, TCR-triggered Lck dephosphorylation at the inhibitory Tyr505 residue was conserved, which suggested normal activation of the CD45 phosphatase. DGK $\alpha$ silenced cells showed the characteristic Lck shift that results from ERK-dependent Ser/Thr phosphorylation and protects the enzyme from SHIP dephosphorylation [30]. This suggested an Lck activation deficit rather than enhanced phosphatase activity. TCR triggering of Lck facilitates ZAP70 activation [31] and subsequent phosphorylation of the LAT (linker for activation of T cells) and SLP76 scaffolds, which provide anchoring phospho-tyrosine residues for signaling proteins such as PLC $\gamma$ (phospholipase C-gamma). Western blot analysis confirmed a reduction in PLC $\gamma$ and ZAP70 phosphorylation in DGK $\alpha$-silenced cells (Fig. 3c). Overexposure of blot membranes with the anti-pSrc family kinase $\mathrm{Ab}$ showed recognition of some proteins whose $\mathrm{Mw}$ corresponded to PLC $\gamma$ and ZAP70, and whose phosphorylation was also reduced in DGKo ${ }^{-/-}$thymocytes (Supplementary Fig. 3a).

Contrary to observations in DGK $\alpha$-depleted cells, pharmacological DGK $\alpha$ inhibition promoted pTyr394 Lck in wt mouse thymocytes and in Jurkat cells (Fig. 3d-e). Total phospho-tyrosine profiles showed that the inhibitor promoted subtle increases (Supplementary Fig. 3c-d). These results confirm opposite effects of DGK $\alpha$ depletion or inhibition on Lck activation, and suggest that DGK $\alpha$ inhibition promotes TCR-dependent Lck activation.

\section{Differential regulation of long-term effects by ritanserin and R59949 in primary mouse T cells}

Cell surface expression of the early activation marker CD69 is a direct measure of Ras/ERK activation, whereas the IL-2 receptor $\alpha$ chain $\mathrm{CD} 25$ is a late activation marker that confers high affinity for IL-2 in activated T cells. Analysis of Jurkat $\mathrm{T}$ cells showed increased percentages of $\mathrm{CD} 69^{+} \mathrm{CD} 25^{+}$cells in response to R59949 or ritanserin treatment (Supplementary Fig. 4a-c). Drug treatment increased expression per cell of both markers, with greater CD69 increases at early times. To determine whether the effects of these drugs were due to DGK $\alpha$ targeting and not to 5-HTR, we compared their influence on CD69 expression with that of ketanserin. Only R59949 and ritanserin enhanced expression of this marker (Supplementary Fig. 4d).

R59949 treatment in primary mouse $\mathrm{T}$ cells also enhanced overall CD69 expression, which was higher after CD28 costimulation; contrary to observations in Jurkat T cells, ritanserin did not reproduce this effect (Fig. 4a, left). The effect of R59949 on CD69 expression was minor in DGK $\alpha^{-/-}$cells, and was lost at later times (Fig. 4a, right). R59949 addition to anti-CD3-stimulated wt cells induced CD25 levels similar to those found after CD28 costimulation (Fig. 4b, left), an effect again lost in DGK $\alpha^{-/-}$cells. Ritanserin treatment did not increase CD25 expression in wt cells and markedly reduced its expression in $\mathrm{DGK}^{-/-}$cells (Fig. 4b, right). R59949 also increased CD69 and CD25 expression in OT-I mouse $\mathrm{CD}^{+} \mathrm{T}$ cells (Supplementary Fig. 5).

Our experiments suggest a differential effect for ritanserin and R59949 in mouse T cells. Mouse T cells synthesize 5-HT, which exercises costimulatory functions through 5-HTR $2 \mathrm{a}$ [32] and 5-HTR 7 [33], whose expression we corroborated by RT-PCR in activated wt and DGK $\alpha^{-1-} \mathrm{T}$ cells (Supplementary Fig. 6a). As the result of antagonistic effects on 5-HT receptors, ritanserin limits murine T-cell 
a Thymocytes

Crosslinking anti-CD3 mAb + anti-CD28 mAb

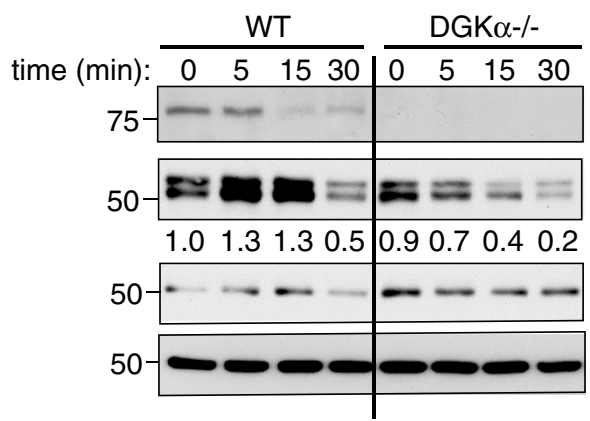

DGK $\alpha$

pSrc family (pTyr394)

p59Lck

$\alpha$ tubulin b

Jurkat

Anti-CD3 mAb + anti-CD28 mAb

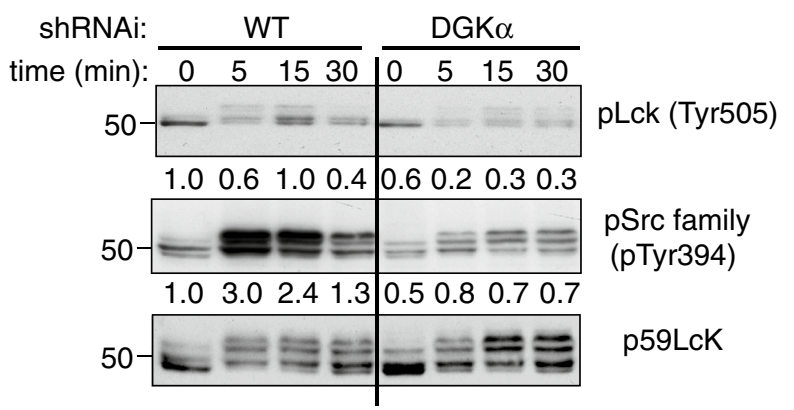

C

Jurkat

Anti-CD3 mAb + anti-CD28 mAb

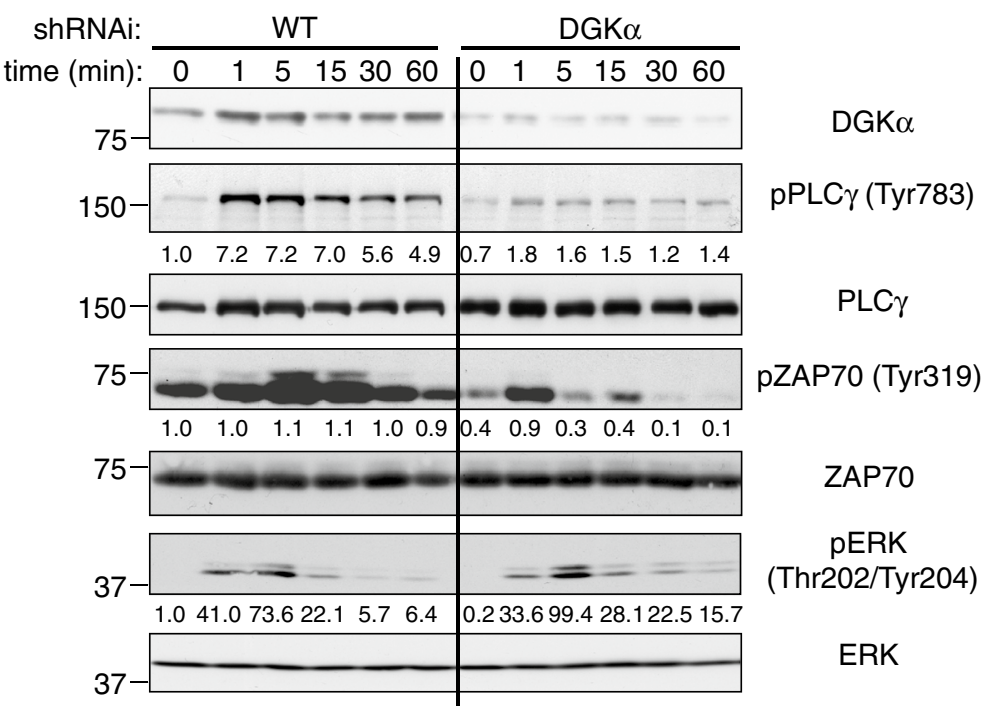

d

Thymocytes

Anti-CD3 mAb + anti-CD28 mAb

DMSO

R59949

\begin{tabular}{|c|c|c|c|c|c|}
\hline \multirow[b]{2}{*}{ time $(\min )$ : } & & & & & \\
\hline & 5 & 15 & 30 & $\begin{array}{llll}0 & 5 & 15 & 30 \\
\end{array}$ & \multirow{2}{*}{$\begin{array}{c}\text { pSrc family } \\
\text { (pTyr394) }\end{array}$} \\
\hline 50 & 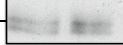 & 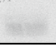 & 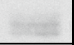 & $=2 x=1=$ & \\
\hline & 1.01 .1 & 0.5 & 0.8 & $\begin{array}{llll}0.6 & 3.8 & 2.2 & 2.1\end{array}$ & \\
\hline 37 & $-\infty$ & & & $-\infty-\infty=0$ & GAPDH \\
\hline
\end{tabular}

Fig. 3 DGK $\alpha$ is a component of the TCR pathway that promotes Lck activation. a Thymus T cells from wt or DGK $\alpha^{-/-}$mice were crosslinked with anti-CD3/CD28 for various times, and Lck phosphorylation analyzed with indicated $\mathrm{Ab}$. b, $\mathbf{c}$ Control or DGK $\alpha$-silenced Jurkat $\mathrm{T}$ cells were stimulated with anti-CD3/CD28 for different times. Lysates were analyzed with indicated Ab. d Thymus $\mathrm{T}$ cells from a wt mouse were stimulated with anti-CD3/CD28 alone or with

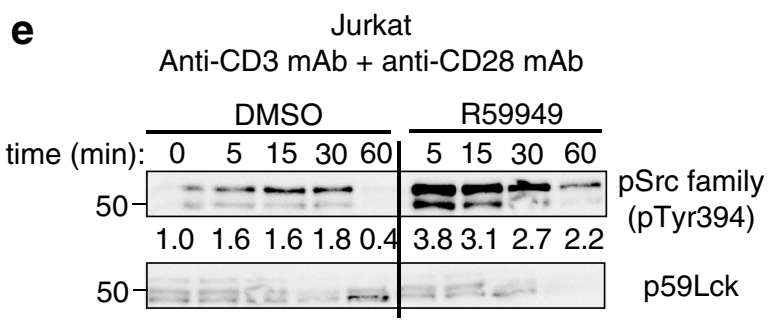

R59949 for indicated times. Lck-activating phosphorylation was analyzed by western blot. e Jurkat cells were stimulated and analyzed as in d. In a-e Lck or ZAP70, $\alpha$-tubulin, and GAPDH were used as loading controls. Normalized values are indicated beneath the blots. In all cases, results are representative of three experiments with similar results 
proliferation and CD25 induction triggered by pharmacological agents [34]. Ligand competition assays indicate that R59949 is less effective than ritanserin in antagonizing 5-HTR 7 [15]. Differential 5-HTR 7 targeting by R59949 and ritanserin could thus explain their distinct effects on T-cell activation; this is supported by observations that ketanserin also reduced CD69 and CD25 expression in primary mouse cells (Supplementary Fig. 6b-c).

\section{DGKa inhibition cooperates with DGK乙 silencing for NFkB-regulated transcription}

Our experiments in primary $\mathrm{T}$ cells showed that pharmacological targeting of DGK $\alpha$ enhances CD25 expression, a T-cell activation signature dependent on the costimulatory pathway. We recently identified DGK $\zeta$ predominance over DGK $\alpha$ in the regulation CD28-dependent signals that ultimately control NFKB transcription [19]. We tested whether in contrast to DGK $\alpha$ silencing, pharmacological DGK $\alpha$ inhibition enhances NFKB activation. R59949 treatment of CD3/CD28-stimulated Jurkat T cells increased NFKB transcription, with a lesser ritanserin effect (Fig. 5a). NFkBregulated transcription did not increase in DGK $\alpha$-silenced Jurkat $\mathrm{T}$ cells, confirming the previous findings [19], and as predicted, pharmacological inhibitors had a negligible effect. In contrast, inhibitor treatment further enhanced $\mathrm{NFKB}$ transcription in DGK $\zeta$-silenced cells (Fig. 5a). In accordance with its effect on $\mathrm{NF \kappa B}$ transcription activity,

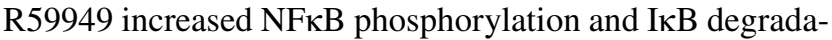
tion (Fig. 5b).

The NFkB pathway is crucial for IL-2 expression. The IL-2 promoter has two NFKB recognition sites that ensure IL-2 expression in fully activated cells, and deficient IL-2 production is a hallmark of anergic cells [35]. Silencing of DGK $\zeta$, but not DGK $\alpha$, enhances IL-2 promoter activation [19], as confirmed here. As seen for AP-1 and NFKB transcription, we observed cooperation between DGK $\alpha$ pharmacological inhibition and DGK $\zeta$ silencing (Fig. 5c). These data corroborate experiments in $\mathrm{DGK} \zeta^{-1-}$ mice showing that R59949 enhances the anergy-resistant phenotype of $\mathrm{DGK}^{-1-}$ primary T cells [36], and confirm that DGK $\alpha$ inhibition amplifies TCR and costimulatory signals, even in the absence of DGK $\zeta$.

\section{Effect of DGKa inhibition in PBMC}

DGK $\alpha$ limits naïve T-cell activation, but is crucial for maintaining the hypofunctional state of TIL [10]. Tumor cells promote T-cell anergy by upregulating negative regulators of T-cell function such as cytosolic molecules and inhibitory receptors. The PD-1/PD-L1 axis is a central target of anti-tumor immunotherapies [37]; this interaction enables recruitment of tyrosine phosphatase SHP2, which limits activation downstream of the TCR [38]. Pharmacological DGK $\alpha$ inhibition enhanced Lck activation, which suggests that this function competes with that of PD-1. Using a well-characterized model [39], we tested the effect of R59949-dependent DGK $\alpha$ inhibition in human healthy donor $\mathrm{T}$ cells fully stimulated with beads coated with anti-CD3/CD28 Ab alone or with PD-L1. As we found in mouse T cells and the Jurkat T-cell line, R59949 treatment of human primary $\mathrm{T}$ cells increased the percentage of $\mathrm{CD} 69^{+} \mathrm{CD} 25^{+} \mathrm{T}$ cells and expression of both markers (Fig. 6; Supplementary Fig. 7).

PD-1 triggering greatly reduced T-cell activation, an effect that R59949 did not reverse completely (Fig. 6a). Comparison of normalized values nonetheless showed that R59949 potentiated the percentage of double-positive cells and CD25 expression, regardless of PD-1 (Fig. 6b-d). We suggest that since PD-1 limits TCR tyrosine signaling, it also limited DGK $\alpha$ activation and, therefore, the amount of DGK $\alpha$ accessible to the inhibitor.

\section{Discussion}

DGK-mediated consumption of DAG generated in response to $\mathrm{Ag}$ recognition offers an opportunity for therapeutic manipulation of the immune response. Several studies indicate that $\mathrm{DGK} \zeta$ predominates over DGK $\alpha$ in TCR response control $[19,40,41]$. A minor DGK $\alpha$ contribution is probably the result of TCR/costimulation-triggered mechanisms that lead to early DGK $\alpha$ inhibition [42] and, at later times, to transcriptional repression [18]. Although at first glance, this would discourage use of DGK $\alpha$ in favor of DGK $\zeta$ as a therapeutic target, additional considerations support interest in DGK $\alpha$. In conditions in which costimulatory pathways are lacking or IL-2 concentration is low, DGK $\alpha$ might be activated disproportionately [18]. Increased DGK $\alpha$ levels are found in pathological states, as is the case of tumorinfiltrating $\mathrm{T}$ and NK cells $[10,43]$. DGK $\alpha$ expression also increases in cancer cell lines forced to grow in conditions that mimic the tumor microenvironment, or are treated with anti-tumor drugs [29]. DGK $\alpha$ blockade reduces in vivo tumor cell growth in models of xenografted cancer cells $[29,44]$. The dual function of DGK $\alpha$ can thus be exploited to block tumor growth and enhance the anti-tumor immune response. Detailed understanding of the effects of DGK $\alpha$ pharmacological inhibition is needed to delineate its use as a drug target and to define the characteristics desired in new inhibitors. Here we compared the effects of DGKiI and II and ritanserin to those of enzyme silencing or deletion in distinct TCR-activated pathways.

Our study addressed ritanserin function as a DGK $\alpha$ inhibitor in T lymphocytes. Ritanserin mimicked R59949 effects and promoted early T-cell signaling, but these two 
a

wt
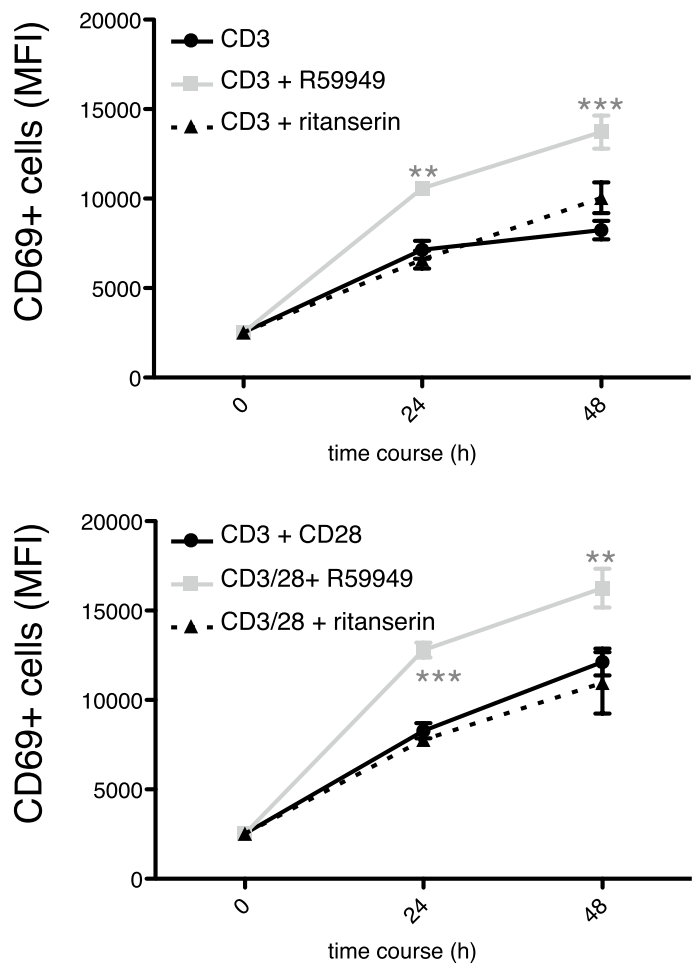

b

wt
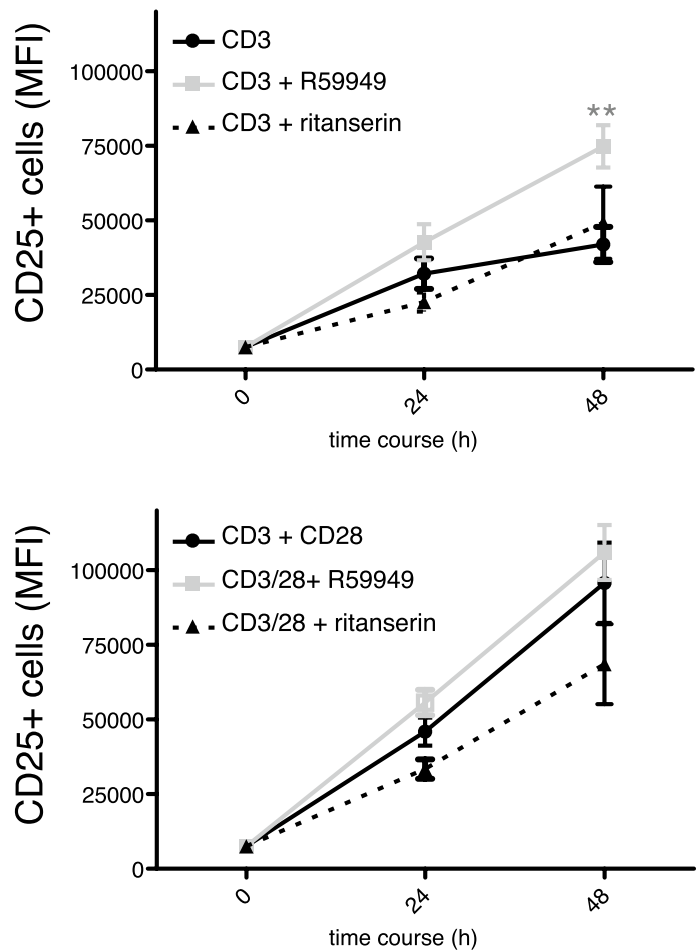

DGK $\alpha-/-$
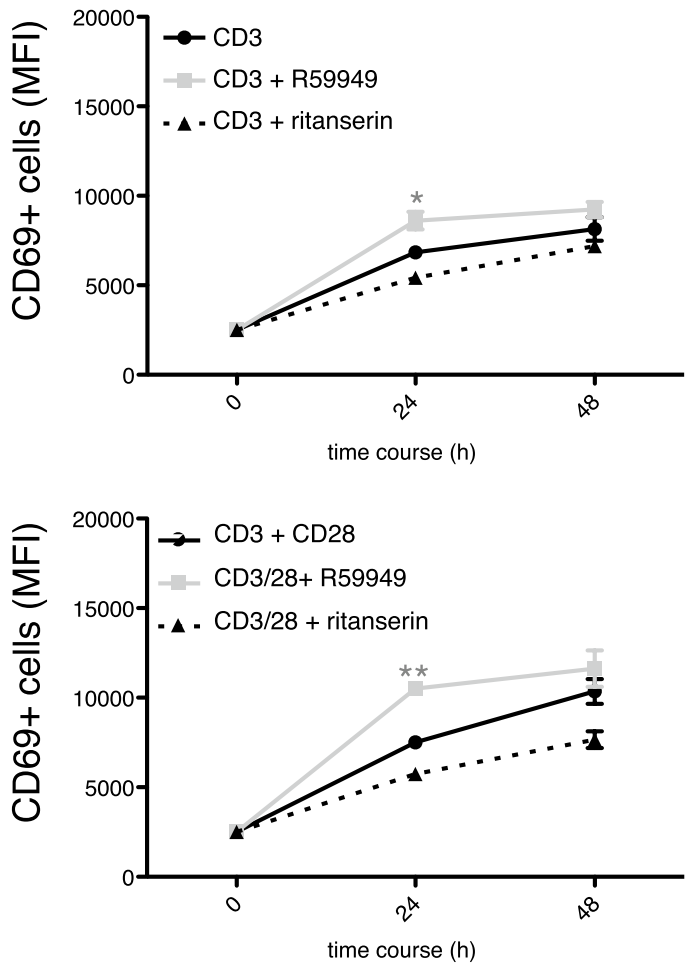

DGK $\alpha-/-$
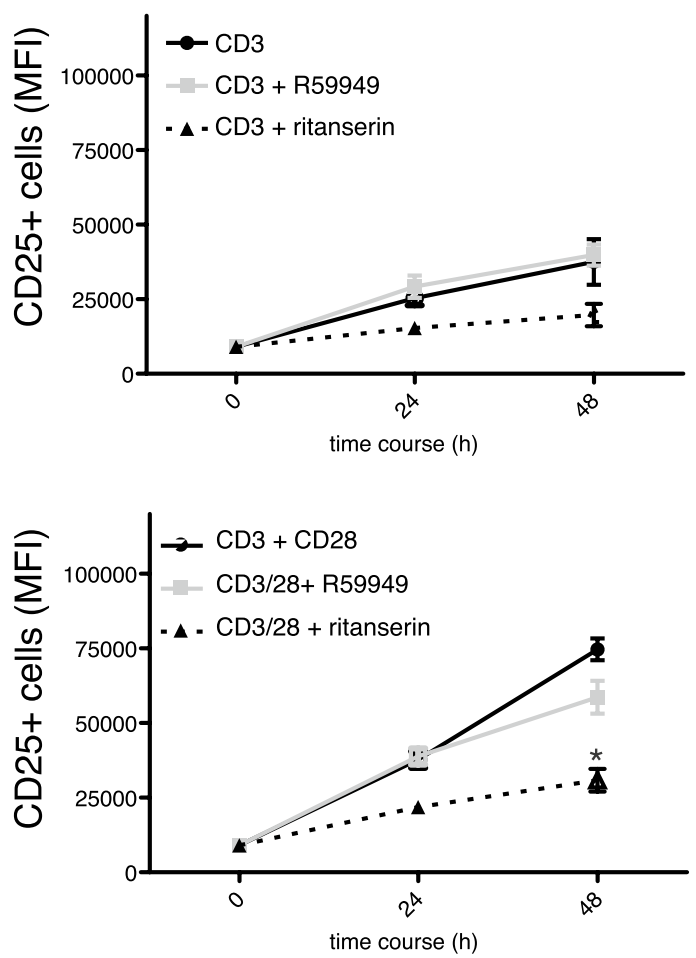
४Fig. 4 R59949, but not ritanserin, promotes CD69 and CD25 expression after TCR triggering and costimulation in mouse T cells. Naïve $\mathrm{LN}$ cells from $\mathrm{C} 57 \mathrm{BL} / 6 \mathrm{~J}$ wt and $\mathrm{DGK} \alpha^{-/-}$mice were stimulated with anti-CD3 or $-\mathrm{CD} 3 / \mathrm{CD} 28 \mathrm{mAb}$ for indicated times, alone or with R59949 or ritanserin. Cell surface CD69 and CD25 expression were analyzed by flow cytometry in $\mathrm{CD}^{+} \mathrm{T}$ cells. MFI are shown for a CD69 and b CD25. Data shown as mean \pm SEM; $n=3$ mice/ genotype; results are representative of three experiments with similar results. Data were analyzed using two-way ANOVA and Bonferroni post-test

inhibitors had distinct long-term effects. Differences were more pronounced in primary mouse lymphocytes, in which ritanserin repressed CD25 expression. This negative effect of ritanserin concurs with its $5-\mathrm{HTR}_{2}$ antagonist effect in mouse $T$ cells [34], and was more evident in the absence of DGK $\alpha$. We propose that differential $5-\mathrm{HTR}_{7}$ targeting by R59949 and ritanserin explains their distinct long-term effects. Ligand competition assays showed that R59949 and R59022 have antagonist activity to all 5-HTR, although R59949 blocks 5-HTR 2 c and 5-HTR 7 less effectively than R59022 [15], which more closely resembles ritanserin. The expression pattern of distinct 5-HTR in PBMC and in TIL must thus be considered for potential ritanserin repositioning as a T-cell modulator.

Our studies validate DGK $\alpha$ targeting by R59949 and demonstrate that DGK $\alpha$ inhibition has no effect on basal ERK phosphorylation or CD69 expression. This finding confirms that, despite $\mathrm{DGK} \alpha$ abundance in naïve $\mathrm{T}$ cells, its inhibition only amplifies Ras/ERK signaling after TCR triggering. This correlates with the $\mathrm{DGK} \alpha$ requirement for TCR-derived signals for activation, including Lck-dependent phosphorylation and $\mathrm{Ca}^{2+}$ binding. It also supports observations that, at difference from $\mathrm{DGK} \zeta$, genetic deletion of DGK $\alpha$ has no effect in basal conditions [19]. Our data showing lack of R59949 or ritanserin gain-of-function effects on DGK $\alpha$-silenced or -deficient cells argue for preferential targeting of DGK $\alpha$. The increased R59949 action in DGK $\zeta$ lacking cells suggests cooperative control of TCR-derived signals by both isoforms.

As R59949 binds the DGK $\alpha$ catalytic region [16], we hypothesized that this leads to membrane localization of the enzyme in a conformation that increases its scaffolding and TCR-triggering functions. The inhibitory effect might thus be envisaged as gain-of-function, which would correlate with reported DGK $\alpha$ inhibition by costimulatory signals [42]. This hypothesis is supported by DGK $\alpha$ maintenance at the plasma membrane as induced by R59949 and its ana$\operatorname{logs}$ (R59022 and ritanserin). TCR stimulation results in a $\mathrm{Ca}^{2+}$ increase and tyrosine phosphorylation, signals needed to induce the conformational changes necessary for DGK $\alpha$ binding to the membrane; at the membrane, $\mathrm{Mg}^{2+}$ and ATP would help stabilize R59949 binding [16]. Ritanserin binds to the DGK $\alpha$ catalytic domain and to its first $\mathrm{C} 1$ domain [45]; the open membrane-bound enzyme might expose its $\mathrm{C} 1$ domains, which would further potentiate DGKi binding. These observations imply a link between the kinase domain-binding capacity of the inhibitors, DGK $\alpha$ membrane stabilization, and inhibition potency, all of which must be considered in the design and evaluation of new DGK $\alpha$ inhibitors.

Lck-mediated tyrosine phosphorylation of DGK $\alpha$ is necessary for its association to the T-cell plasma membrane [28]. In a previous study, we proposed that DGK $\alpha$ interaction with Src kinases promotes their unclamping and facilitates their activation in cancer cells [29]. Our data here suggest a similar DGK $\alpha$ function in promoting Lck activation and signaling in T cells. DGK $\alpha$ activity has also been linked to endosomal recycling of HLA-I in HeLa cells [46] and of integrin in breast cancer cells [47]. Inhibition of DGK $\alpha$ in response to costimulatory signals could prevent integrin recycling, supporting additional mechanisms for Lck activation at the plasma membrane. The positive effect of DGK $\alpha$ inhibition on Lck described here might also be relevant for other Src kinase family members in T cells; for instance, $\mathrm{DGK} \alpha$ pharmacological inhibition restores PKC $\theta$ association to Fyn in SAP-deficient T cells [42].

Impaired Lck activation in DGK $\alpha$-silenced or -deficient cells correlated with reduced PLC $\gamma$ phosphorylation, which suggests decreased DAG production and signaling. This finding contrasts with the enhanced ERK phosphorylation we observed in these cells here and that coincides with previous reports [9, 19, 48]. Compensation and/or additional mechanisms that lead to ERK activation might be operative, as occurs in the absence of canonical Lck-Zap70-PLC $\gamma$ activation [49]. Whereas ERK activation occurs in such conditions, insufficient tyrosine kinase activation might affect correct cytoskeleton organization during Ag recognition. Murine DGK $\alpha^{-1-}$ T cells do not polarize mTOC during immune synapse formation, which concurs with actin remodeling alterations [12]. This deficit correlates with the role of Lck in actin reorganization at the immunological synapse [50]. The potential DAG signaling gain due to DGK $\alpha$ loss might be offset by the reduced polarity and DAG production [12], which could explain the lesser contribution of DGK $\alpha$ compared with that of DGK $\zeta$ in regulating TCRDAG-promoted signals [7].

The PD-1/PD-L1 axis blunts TCR-induced tyrosine phosphorylation, and thus the mechanisms that promote DGK $\alpha$ aperture/activation, which would limit DGK $\alpha$ targeting by the inhibitors. This would explain why R59949 treatment is unable to counteract PD-1 effects completely in our experiments with human $\mathrm{T}$ cells. Experiments with renal carcinoma TIL showed PLC $\gamma$ phosphorylation in response to TCR stimulation [10]; this suggests that 
Fig. 5 DGK $\alpha$ inhibition, but not silencing, promotes NFKB activity. a Luciferase activity of an NFkB reporter construct was measured in control and DGK $\alpha$ or DGK $\zeta$-silenced Jurkat T cells, after stimulation with anti-CD3/CD28 mAb alone or with R59949 or ritanserin. Luciferase activity was corrected using an internal renilla luciferase control. b Jurkat T cells were stimulated with anti$\mathrm{CD} 3 / \mathrm{CD} 28 \mathrm{mAb}$ for indicated times, alone or with R59949. $\mathrm{NF \kappa B}$ phosphorylation and I $\mathrm{B}$ degradation were analyzed with indicated $\mathrm{Ab}$. $\alpha$-tubulin was used as loading control. c IL-2 promoter activity was determined as in $\mathbf{a}$. In $\mathbf{a}, \mathbf{c}$ data shown as mean $\pm \mathrm{SEM} ; n=3$ independent transfections per shRNAi construct. Results are representative of at least three independent series of experiments with similar results. Data were analyzed using two-way ANOVA and Bonferroni posttest, and results of comparisons are summarized in the tables

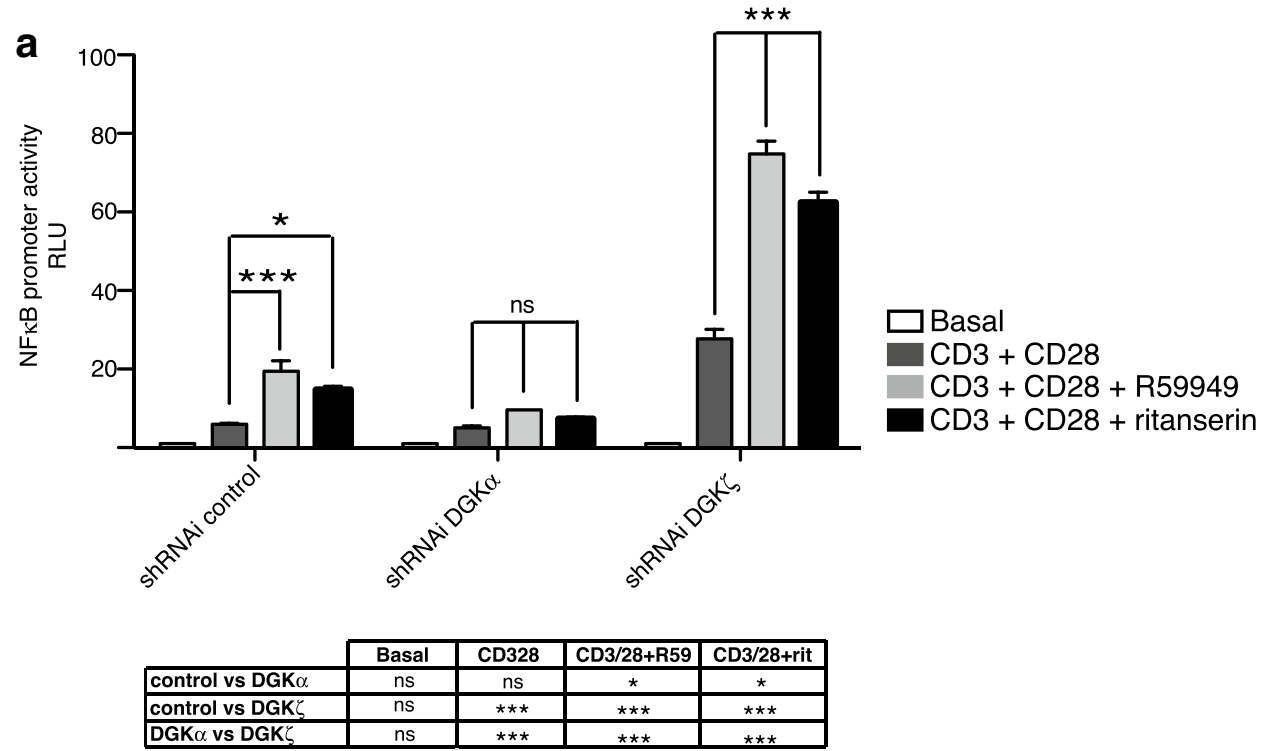

Anti-CD3 mAb + anti-CD28 mAb

DMSO

R59949
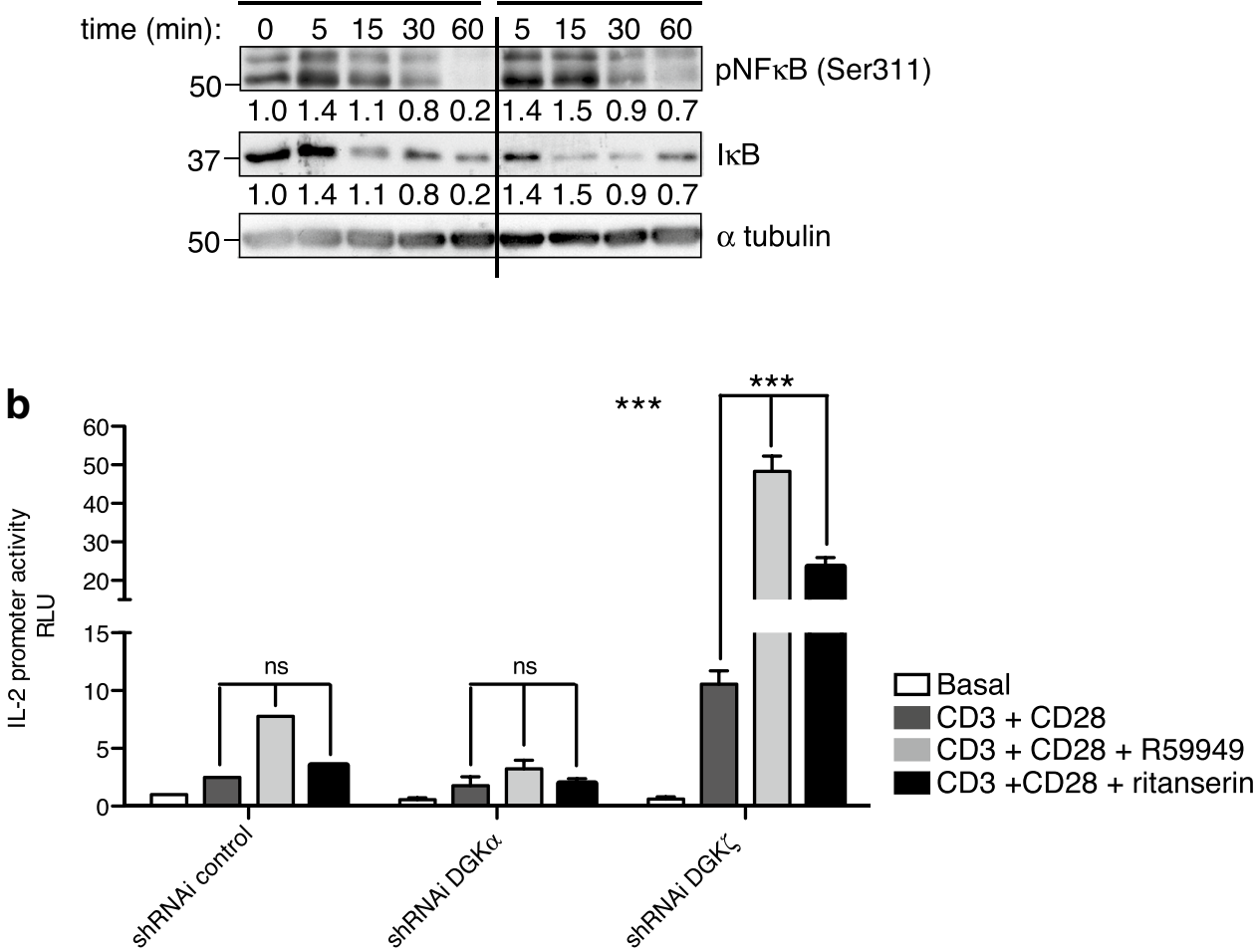

\begin{tabular}{|l|c|c|c|c|}
\cline { 2 - 5 } \multicolumn{1}{c|}{} & Basal & CD328 & CD3/28+R59 & CD3/28+rit \\
\hline control vs DGK $\alpha$ & $\mathrm{ns}$ & $\mathrm{ns}$ & $\mathrm{ns}$ & $\mathrm{ns}$ \\
\hline control vs DGK $\zeta$ & $\mathrm{ns}$ & $\mathrm{ns}$ & $\star \star \star$ & $\star \star \star$ \\
\hline DGK $\alpha$ vs DGK $\zeta$ & $\mathrm{ns}$ & $\star$ & $\star \star \star$ & $\star \star \star$ \\
\hline
\end{tabular}

tyrosine signaling in TIL is not entirely blocked by the action of negative receptors, and that DGK $\alpha$ is accessible to pharmacological inhibition. Whether alone or combined with PD-1-blocking therapies, DGK $\alpha$ inhibition would enhance the intensity of antigen-triggered signals and foster an immune response to cancer cells. 
Fig. 6 DGK $\alpha$ inhibition increases CD69 and CD25 expression after TCR costimulation or the PD-1/PD-L1 immune checkpoint. Purified $\mathrm{CD} 8^{+} \mathrm{T}$ cells from donors (D1-D3), were stimulated with IgG, anti-CD3/CD28 or -CD3/ CD28 + PD-L1-coated beads for indicated times, alone or with R59949. CD69 and CD25 induction were analyzed by flow cytometry. a Percentage of CD $69^{+} \mathrm{CD} 25^{+} \mathrm{CD} 8^{+} \mathrm{T}$ cells. b Fold increase in the percentage of activated cells normalized to the respective DGKi-untreated condition. $\mathbf{c}$ Fold change of the MFI of CD69 and $\mathbf{d}$ CD25 was normalized to the respective DGKi-untreated condition. Data were analyzed using two-way ANOVA and Bonferroni posttest
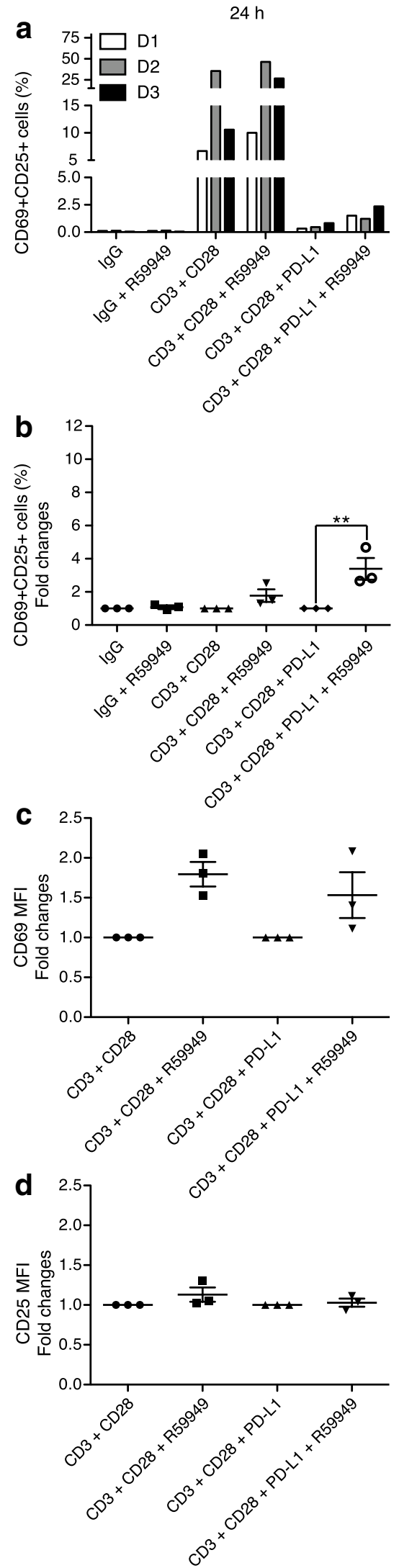
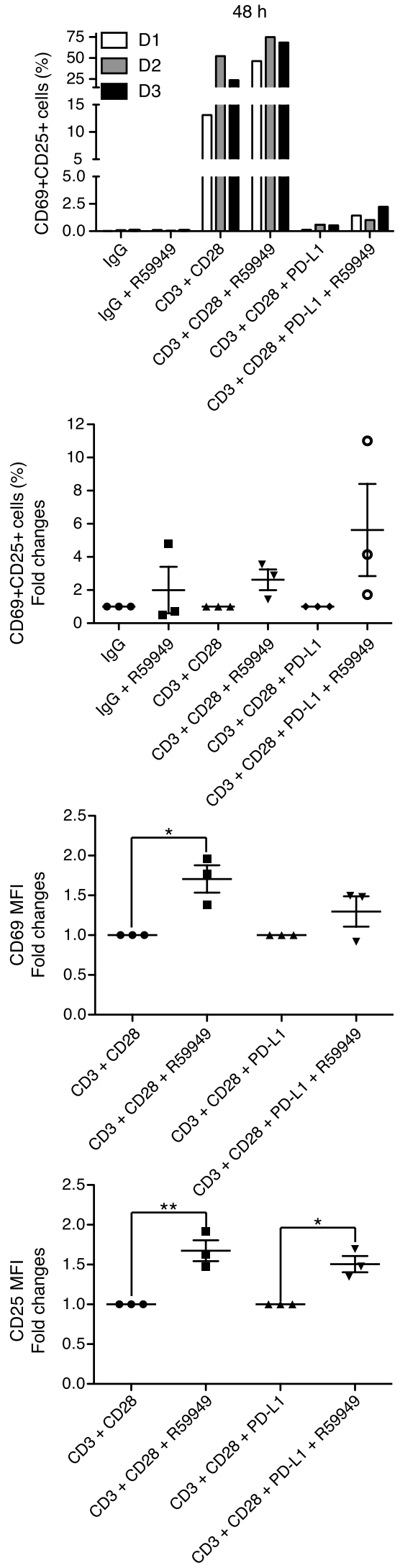
Acknowledgements We thank Rosa Liébana for maintenance of the mouse colonies and technical assistance in the isolation of mouse cells, Alejandra Cordero for technical assistance, Carmen Moreno for technical assistance in cytometry data acquisition, and Catherine Mark for excellent editorial assistance.

Author contributions Javier Arranz-Nicolás and Antonia Ávila-Flores performed mouse and Jurkat cell experiments, acquired, analyzed and interpreted data, and prepared the figures. Jesús Ogando performed the PBMC experiments and acquired the data. Jesús Ogando and Santos Mañes interpreted the PBMC data. Denise Soutar performed mouse experiments. Daniel Meraviglia-Crivelli and Raquel ArcosPérez performed Jurkat and mouse cells RT-PCR experiments. Raquel Arcos-Pérez developed the luciferase constructs. Antonia Ávila-Flores and Isabel Mérida designed and supervised the study, interpreted the data and wrote the manuscript. All authors read and gave input on the manuscript.

Funding Javier Arranz-Nicolás and Jesús Ogando hold predoctoral FPI fellowships from the Spanish Ministry of Economy and Competitiveness (MINECO). This work was supported in part by grants from the MINECO/FEDER/EU (BFU2016-77207-R), Spanish Ministry of Health (Instituto de Salud Carlos III; RD12/0036/0059) to Isabel Mérida, MINECO/FEDER/EU (SAF2017-83732-R) to Santos Mañes, and from the Madrid regional government (IMMUNOTHERCAM Consortium CM B2017/BMD3733) to Isabel Mérida and Santos Mañes.

\section{Compliance with ethical standards}

Conflict of interest The authors declare no potential conflicts of interest.

Ethical approval Mice were maintained and handled in accordance with Spanish and European directives. All procedures performed with animals were conducted according the protocols approved by the $\mathrm{CNB} /$ CSIC Ethics Committee on Animal Experimentation (RD53/2013). PBMC were from the Blood Transfusion Center, Red Cross (Madrid, Spain), obtained with appropriate informed consent from the donors. No personal data were registered and all procedures performed with these cells were in accordance with the ethical standards of the CNB/ CSIC Ethics Committee.

Animal source $\mathrm{C} 57 \mathrm{BL} / 6 \mathrm{~J}-\mathrm{DGK} \alpha^{-/-}$mice were kindly donated by $\mathrm{Dr}$. Xiao-Ping Zhong (Duke University Medical Center, Durham NC). C57BL/6J-DGK $\zeta^{-l-}$ mice were a gift of Dr. Gary Koretzky (University of Pennsylvania, Philadelphia PA). These mouse lines were used to generate the corresponding OT-I DGK ${ }^{-/-}$mice. The colonies were maintained in pathogen-free conditions in the CNB animal facility, following institutional guidelines.

Cell line authentication Human leukemic Jurkat T cells were authenticated by polymorphic short tandem repeat (STR) locus analysis (Genomics Service, Centro de Investigaciones Biomédicas-CSIC).

\section{References}

1. Singh N, Frey NV, Grupp SA, Maude SL (2016) CAR T cell therapy in acute lymphoblastic leukemia and potential for chronic lymphocytic leukemia. Curr Treat Options Oncol 17(6):28. https ://doi.org/10.1007/s11864-016-0406-4
2. Pardoll DM (2012) The blockade of immune checkpoints in cancer immunotherapy. Nat Rev Cancer 12(4):252-264. https://doi. org/10.1038/nrc3239

3. Robert C, Ribas A, Wolchok JD, Hodi FS, Hamid O, Kefford R, Weber JS, Joshua AM, Hwu WJ, Gangadhar TC, Patnaik A, Dronca R, Zarour H, Joseph RW, Boasberg P, Chmielowski B, Mateus C, Postow MA, Gergich K, Elassaiss-Schaap J, Li XN, Iannone R, Ebbinghaus SW, Kang SP, Daud A (2014) Antiprogrammed-death-receptor-1 treatment with pembrolizumab in ipilimumab-refractory advanced melanoma: a randomised dosecomparison cohort of a phase 1 trial. Lancet 384(9948):11091117. https://doi.org/10.1016/S0140-6736(14)60958-2

4. Weber JS, D’Angelo SP, Minor D, Hodi FS, Gutzmer R, Neyns B, Hoeller C, Khushalani NI, Miller WH Jr, Lao CD, Linette GP, Thomas L, Lorigan P, Grossmann KF, Hassel JC, Maio M, Sznol M, Ascierto PA, Mohr P, Chmielowski B, Bryce A, Svane IM, Grob JJ, Krackhardt AM, Horak C, Lambert A, Yang AS, Larkin J (2015) Nivolumab versus chemotherapy in patients with advanced melanoma who progressed after anti-CTLA-4 treatment (CheckMate 037): a randomised, controlled, open-label, phase 3 trial. Lancet Oncol 16(4):375-384. https://doi.org/10.1016/S1470 -2045(15)70076-8

5. Moon EK, Wang LC, Dolfi DV, Wilson CB, Ranganathan R, Sun J, Kapoor V, Scholler J, Pure E, Milone MC, June CH, Riley JL, Wherry EJ, Albelda SM (2014) Multifactorial T-cell hypofunction that is reversible can limit the efficacy of chimeric antigen receptor-transduced human $\mathrm{T}$ cells in solid tumors. Clin Cancer Res 20(16):4262-4273. https://doi.org/10.1158/1078-0432. CCR-13-2627

6. Merida I, Avila-Flores A, Merino E (2008) Diacylglycerol kinases: at the hub of cell signalling. Biochem J 409(1):1-18

7. Merida I, Andrada E, Gharbi SI, Avila-Flores A (2015) Redundant and specialized roles for diacylglycerol kinases alpha and zeta in the control of T cell functions. Sci Signal 8(374):re6. https://doi. org/10.1126/scisignal.aaa0974

8. Macian F, Garcia-Cozar F, Im SH, Horton HF, Byrne MC, Rao A (2002) Transcriptional mechanisms underlying lymphocyte tolerance. Cell 109(6):719-731

9. Olenchock BA, Guo R, Carpenter JH, Jordan M, Topham MK, Koretzky GA, Zhong XP (2006) Disruption of diacylglycerol metabolism impairs the induction of T cell anergy. Nat Immunol 7(11):1174-1181

10. Prinz PU, Mendler AN, Masouris I, Durner L, Oberneder R, Noessner E (2012) High DGK-alpha and disabled MAPK pathways cause dysfunction of human tumor-infiltrating CD8 $+\mathrm{T}$ cells that is reversible by pharmacologic intervention. J Immunol 188(12):5990-6000. https://doi.org/10.4049/jimmunol.1103028

11. Sato M, Liu K, Sasaki S, Kunii N, Sakai H, Mizuno H, Saga H, Sakane F (2013) Evaluations of the selectivities of the diacylglycerol kinase inhibitors R59022 and R59949 among diacylglycerol kinase isozymes using a new non-radioactive assay method. Pharmacology 92(1-2):99-107. https://doi.org/10.1159/000351849

12. Chauveau A, Le Floc'h A, Bantilan NS, Koretzky GA, Huse M (2014) Diacylglycerol kinase alpha establishes T cell polarity by shaping diacylglycerol accumulation at the immunological synapse. Sci Signal 7(340):ra82. https://doi.org/10.1126/scisi gnal.2005287

13. Leysen JE, Gommeren W, Van Gompel P, Wynants J, Janssen PF, Laduron PM (1985) Receptor-binding properties in vitro and in vivo of ritanserin: a very potent and long acting serotonin-S2 antagonist. Mol Pharmacol 27(6):600-611

14. Akhondzadeh S, Mohajari H, Reza Mohammadi M, Amini H (2003) Ritanserin as an adjunct to lithium and haloperidol for the treatment of medication-naive patients with acute mania: a double blind and placebo controlled trial. BMC Psychiatry 3:7. https:// doi.org/10.1186/1471-244X-3-7 
15. Boroda S, Niccum M, Raje V, Purow BW, Harris TE (2017) Dual activities of ritanserin and R59022 as DGKalpha inhibitors and serotonin receptor antagonists. Biochem Pharmacol 123:29-39. https://doi.org/10.1016/j.bcp.2016.10.011

16. Jiang Y, Sakane F, Kanoh H, Walsh JP (2000) Selectivity of the diacylglycerol kinase inhibitor 3-[2-(4-[bis-(4-fluorophenyl) methylene]-1-piperidinyl)ethyl]-2, 3-dihydro-2-thioxo-4(1H) quinazolinone (R59949) among diacylglycerol kinase subtypes. Biochem Pharmacol 59(7):763-772

17. Purow B (2015) Molecular pathways: targeting diacylglycerol kinase alpha in cancer. Clin Cancer Res 21(22):5008-5012. https ://doi.org/10.1158/1078-0432.CCR-15-0413

18. Martinez-Moreno M, Garcia-Lievana J, Soutar D, Torres-Ayuso P, Andrada E, Zhong XP, Koretzky GA, Merida I, Avila-Flores A (2012) FoxO-dependent regulation of diacylglycerol kinase alpha gene expression. Mol Cell Biol 32(20):4168-4180. https://doi. org/10.1128/MCB.00654-12

19. Ávila-Flores A, Arranz-Nicolás J, Andrada E, Soutar D, Mérida I (2017) Predominant contribution of DGK $\zeta$ over DGK $\alpha$ in the control of PKC/PDK-1-regulated functions in T cells. Immunol Cell Biol 95(6):549-563. https://doi.org/10.1038/icb.2017.7

20. Desai DM, Newton ME, Kadlecek T, Weiss A (1990) Stimulation of the phosphatidylinositol pathway can induce T-cell activation. Nature 348(6296):66-69. https://doi.org/10.1038/348066a0

21. Sanjuan MA, Jones DR, Izquierdo M, Merida I (2001) Role of diacylglycerol kinase alpha in the attenuation of receptor signaling. J Cell Biol 153(1):207-220

22. Schaap D, van der Wal J, van Blitterswijk WJ, van der Bend RL, Ploegh HL (1993) Diacylglycerol kinase is phosphorylated in vivo upon stimulation of the epidermal growth factor receptor and serine/threonine kinases, including protein kinase C-epsilon. Biochem J 289(Pt 3):875-881

23. Sanjuan MA, Pradet-Balade B, Jones DR, Martinez AC, Stone JC, Garcia-Sanz JA, Merida I (2003) T cell activation in vivo targets diacylglycerol kinase alpha to the membrane: a novel mechanism for Ras attenuation. J Immunol 170(6):2877-2883

24. Aune TM, Kelley KA, Ranges GE, Bombara MP (1990) Serotonin-activated signal transduction via serotonin receptors on Jurkat cells. J Immunol 145(6):1826-1831

25. Dunn GP, Old LJ, Schreiber RD (2004) The three Es of cancer immunoediting. Annu Rev Immunol 22:329-360. https://doi. org/10.1146/annurev.immunol.22.012703.104803

26. Hogquist KA, Jameson SC, Heath WR, Howard JL, Bevan MJ, Carbone FR (1994) T cell receptor antagonist peptides induce positive selection. Cell 76(1):17-27

27. Riese MJ, Grewal J, Das J, Zou T, Patil V, Chakraborty AK, Koretzky GA (2011) Decreased diacylglycerol metabolism enhances ERK activation and augments CD8 + T cell functional responses. J Biol Chem 286(7):5254-5265. https://doi.org/10.1074/jbc. M110.171884

28. Merino E, Avila-Flores A, Shirai Y, Moraga I, Saito N, Merida I (2008) Lck-dependent tyrosine phosphorylation of diacylglycerol kinase alpha regulates its membrane association in T cells. $\mathrm{J}$ Immunol 180(9):5805-5815

29. Torres-Ayuso P, Daza-Martin M, Martin-Perez J, Avila-Flores A, Merida I (2014) Diacylglycerol kinase alpha promotes 3D cancer cell growth and limits drug sensitivity through functional interaction with Src. Oncotarget 5(20):9710-9726. https://doi. org/10.18632/oncotarget.2344

30. Stefanova I, Hemmer B, Vergelli M, Martin R, Biddison WE, Germain RN (2003) TCR ligand discrimination is enforced by competing ERK positive and SHP-1 negative feedback pathways. Nat Immunol 4(3):248-254. https://doi.org/10.1038/ni895

31. Wang H, Kadlecek TA, Au-Yeung BB, Goodfellow HE, Hsu LY, Freedman TS, Weiss A (2010) ZAP-70: an essential kinase in
T-cell signaling. Cold Spring Harb Perspect Biol 2(5):a002279. https://doi.org/10.1101/cshperspect.a002279

32. Inoue M, Okazaki T, Kitazono T, Mizushima M, Omata M, Ozaki S (2011) Regulation of antigen-specific CTL and Th1 cell activation through 5-Hydroxytryptamine $2 \mathrm{~A}$ receptor. Int Immunopharmacol 11(1):67-73. https://doi.org/10.1016/j.intimp.2010.10.007

33. Leon-Ponte M, Ahern GP, O'Connell PJ (2007) Serotonin provides an accessory signal to enhance T-cell activation by signaling through the 5-HT7 receptor. Blood 109(8):3139-3146. https ://doi.org/10.1182/blood-2006-10-052787

34. Young MR, Kut JL, Coogan MP, Wright MA, Young ME, Matthews J (1993) Stimulation of splenic T-lymphocyte function by endogenous serotonin and by low-dose exogenous serotonin. Immunology 80(3):395-400

35. Liao W, Lin JX, Leonard WJ (2013) Interleukin-2 at the crossroads of effector responses, tolerance, and immunotherapy. Immunity 38(1):13-25. https://doi.org/10.1016/j.immun i.2013.01.004

36. Zhong XP, Hainey EA, Olenchock BA, Jordan MS, Maltzman JS, Nichols KE, Shen H, Koretzky GA (2003) Enhanced T cell responses due to diacylglycerol kinase zeta deficiency. Nat Immunol 4(9):882-890

37. Bardhan K, Anagnostou T, Boussiotis VA (2016) The PD1:PDL1/2 pathway from discovery to clinical implementation. Front Immunol 7:550. https://doi.org/10.3389/fimmu.2016.00550

38. Chemnitz JM, Parry RV, Nichols KE, June CH, Riley JL (2004) SHP-1 and SHP-2 associate with immunoreceptor tyrosine-based switch motif of programmed death 1 upon primary human $\mathrm{T}$ cell stimulation, but only receptor ligation prevents $\mathrm{T}$ cell activation. J Immunol 173(2):945-954

39. Patsoukis N, Bardhan K, Chatterjee P, Sari D, Liu B, Bell LN, Karoly ED, Freeman GJ, Petkova V, Seth P, Li L, Boussiotis VA (2015) PD-1 alters T-cell metabolic reprogramming by inhibiting glycolysis and promoting lipolysis and fatty acid oxidation. Nat Commun 6:6692. https://doi.org/10.1038/ncomms7692

40. Gharbi SI, Rincon E, Avila-Flores A, Torres-Ayuso P, Almena M, Cobos MA, Albar JP, Merida I (2011) Diacylglycerol kinase zeta controls diacylglycerol metabolism at the immunological synapse. Mol Biol Cell 22(22):4406-4414. https://doi.org/10.1091/mbc. E11-03-0247

41. Joshi RP, Schmidt AM, Das J, Pytel D, Riese MJ, Lester M, Diehl JA, Behrens EM, Kambayashi T, Koretzky GA (2013) The zeta isoform of diacylglycerol kinase plays a predominant role in regulatory $\mathrm{T}$ cell development and TCR-mediated ras signaling. Sci Signal 6(303):ra102. https://doi.org/10.1126/scisignal.2004373

42. Baldanzi G, Pighini A, Bettio V, Rainero E, Traini S, Chianale F, Porporato PE, Filigheddu N, Mesturini R, Song S, Schweighoffer T, Patrussi L, Baldari CT, Zhong XP, van Blitterswijk WJ, Sinigaglia F, Nichols KE, Rubio I, Parolini O, Graziani A (2011) SAP-mediated inhibition of diacylglycerol kinase alpha regulates TCR-induced diacylglycerol signaling. J Immunol 187(11):59415951. https://doi.org/10.4049/jimmunol.1002476

43. Prinz PU, Mendler AN, Brech D, Masouris I, Oberneder R, Noessner E (2014) NK-cell dysfunction in human renal carcinoma reveals diacylglycerol kinase as key regulator and target for therapeutic intervention. Int J Cancer 135(8):1832-1841. https:// doi.org/10.1002/ijc. 28837

44. Dominguez CL, Floyd DH, Xiao A, Mullins GR, Kefas BA, Xin W, Yacur MN, Abounader R, Lee JK, Wilson GM, Harris TE, Purow BW (2013) Diacylglycerol kinase alpha is a critical signaling node and novel therapeutic target in glioblastoma and other cancers. Cancer Discov 3(7):782-797. https://doi. org/10.1158/2159-8290.CD-12-0215

45. Franks CE, Campbell ST, Purow BW, Harris TE, Hsu KL (2017) The ligand binding landscape of diacylglycerol kinases. Cell 
Chem Biol 24(7):870-880.e5. https://doi.org/10.1016/j.chemb iol.2017.06.007

46. Xie S, Naslavsky N, Caplan S (2014) Diacylglycerol kinase alpha regulates tubular recycling endosome biogenesis and major histocompatibility complex class I recycling. J Biol Chem 289(46):31914-31926. https://doi.org/10.1074/jbc.M114.594291

47. Rainero E, Caswell PT, Muller PA, Grindlay J, McCaffrey MW, Zhang Q, Wakelam MJ, Vousden KH, Graziani A, Norman JC (2012) Diacylglycerol kinase alpha controls RCP-dependent integrin trafficking to promote invasive migration. J Cell Biol 196(2):277-295. https://doi.org/10.1083/jcb.201109112

48. Guo R, Wan CK, Carpenter JH, Mousallem T, Boustany RM, Kuan CT, Burks AW, Zhong XP (2008) Synergistic control of T cell development and tumor suppression by diacylglycerol kinase alpha and zeta. Proc Natl Acad Sci USA 105(33):11909-11914. https://doi.org/10.1073/pnas.0711856105

49. Kortum RL, Rouquette-Jazdanian AK, Miyaji M, Merrill RK, Markegard E, Pinski JM, Wesselink A, Nath NN, Alexander CP, Li W, Kedei N, Roose JP, Blumberg PM, Samelson LE, Sommers CL (2013) A phospholipase C-gamma1-independent, RasGRP1ERK-dependent pathway drives lymphoproliferative disease in linker for activation of T cells-Y136F mutant mice. J Immunol 190(1):147-158. https://doi.org/10.4049/jimmunol.1201458

50. Tsun A, Qureshi I, Stinchcombe JC, Jenkins MR, de la Roche M, Kleczkowska J, Zamoyska R, Griffiths GM (2011) Centrosome docking at the immunological synapse is controlled by Lck signaling. J Cell Biol 192(4):663-674. https://doi.org/10.1083/ jcb. 201008140 